\title{
Osteogenic Differentiation of Miniature Pig Mesenchymal Stem Cells in 2D and 3D Environment
}

\author{
J. JUHÁSOVÁ ${ }^{1}, \check{S ̆}^{\text {. JUHÁS }}{ }^{1}$, J. KLÍMA ${ }^{1}$, J. STRNÁDEL ${ }^{1}$, M. HOLUBOVÁ ${ }^{1}$, J. MOTLÍK ${ }^{1}$ \\ ${ }^{1}$ Institute of Animal Physiology and Genetics, Academy of Sciences, Liběchov, Czech Republic
}

Received May 7, 2010

Accepted November 19, 2010

On-line March 14, 2011

\begin{abstract}
Summary
Mesenchymal stem cells (MSCs) have been repeatedly shown to be able to repair bone defects. The aim of this study was to characterize the osteogenic differentiation of miniature pig MSCs and markers of this differentiation in vitro. Flow-cytometrically characterized MSCs were seeded on cultivation plastic (collagen I and vitronectin coated/uncoated) or plasma clot (PC)/plasmaalginate clot (PAC) scaffolds and differentiated in osteogenic medium. During three weeks of differentiation, the formation of nodules and deposition of calcium were visualized by Alizarin Red Staining. In addition, the production of alkaline phosphatase (ALP) activity was quantitatively detected by fluorescence. The expression of osteopontin, osteonectin and osteocalcin were assayed by immunohistochemistry and Western Blot analysis. We revealed a decrease of osteopontin expression in $2 \mathrm{D}$ and $3 \mathrm{D}$ environment during differentiation. The weak initial osteonectin signal, culminating on $7^{\text {th }}$ or $14^{\text {th }}$ day of differentiation, depends on collagen I and vitronectin coating in 2D system. The highest activity of ALP was detected on $21^{\text {th }}$ day of osteogenic differentiation. The PC scaffolds provided better conditions for osteogenic differentiation of MSCs than PAC scaffolds in vitro. We also observed expected effects of collagen I and vitronectin on the acceleration of osteogenic differentiation of miniature pig MSC. Our results indicate similar ability of miniature pig MSCs osteogenic differentiation in $2 \mathrm{D}$ and $3 \mathrm{D}$ environment, but the expression of osteogenic markers in scaffolds and ECM coated monolayers started earlier than in the monolayers without ECM.
\end{abstract}

\section{Key words}

Cell differentiation - Mesenchymal stem cells • Miniature pig • Scaffold

\section{Corresponding author}

Štefan Juhás, Institute of Animal Physiology and Genetics, CR
Academy of Sciences, Rumburská 89, 27721 Liběchov, Czech Republic. Fax: +420 315639 510. E-mail: juhas@iapg.cas.cz

\section{Introduction}

New therapeutic agents and novel biomaterials for the repair of large bone defects caused by trauma, congenital defects, or bone tumors are still being discovered (Holland and Mikos 2006). One of the promising approaches is the use of mesenchymal cells readily available adult stem cells that, alone or in combination with new biomaterials, have become increasingly popular for use in orthopedic tissue repair and trauma surgery (Heino and Hentunen 2008, Planka et al. 2008, 2009, Gál et al. 2007). In addition a variety of degradable and osteoconductive biomaterials, such as $\beta$ tricalcium phosphates $(\beta-\mathrm{TCP})$, polymethyl methacrylate (PMMA), etc., are available and clinically used (Bodde $e t$ al. 2007, Hautamäki et al. 2008). Similarly, platelet-rich plasma (PRP), a kind of natural source of growth factors, has been used successfully in bone regeneration and improvement of wound healing (Chang et al. 2009). PRP also generated a positive effect on the loading efficiency of MSCs on the highly specific surface CDHA (calciumdeficient hydroxyapatite) and $\beta$-TCP scaffols (Kasten et al. 2008). Another biocompatible and biodegradable polymer, sodium alginate, is frequently used for the encapsulation and immobilization of a variety of cells in tissue engineering. Calcium cross-linked alginate was reported to act as a scaffold for bone marrow cell proliferation and osteogenic differentiation and has a potential for use as 3D degradable scaffold in vitro and in vivo (Abbah et al. 2008, Xu et al. 2005).

Compared with small animal models such as 
rodents, large animal models are superior in many aspects for the study of human diseases and pre-clinical therapies. Miniature pigs have been used as one of the large animal models in medical studies for scientific, economic, and ethical reasons. Miniature pigs are similar to humans in anatomy, development, physiology, pathophysiology, and disease occurrence. There exist many studies describing the miniature pig as a biomodel of wound healing, an object for dental and orofacial research or as a source of organs for xenotransplantation using transgene expression in pig tissues (Wang et al. 2007, Vodicka et al. 2005, Motlík et al. 2007). The use of mesenchymal stem cell intra-articular injections in the miniature pig model was a viable option for treating large cartilage defects without arthrotomy and arthroscopy (Lee et al. 2007). The use of miniature pigs considerably contributed to $3 \mathrm{D}$ geometrical modeling in the treatment of stifle joint cartilage injuries (Krupa et al. 2007). The techniques used for purification, expansion, osteogenic, chondrogenic, and adipogenic differentiation of human MSCs can be adopted for analysis of porcine MSCs, which may meet the increasing demand for stem and progenitor cells in tissue engineering (Ringe et al. 2002). For these reasons, we determined and compared the osteogenic potential of miniature pig MSCs in 2D and 3D environment (plasma clot scaffold or plasma clot/alginate scaffold) by using hematoxylin and eosin (H\&E) staining, Alizarin Red staining, alkaline phosphatase detection, immunodetection and immunohistochemistry.

\section{Materials and Methods}

\section{Isolation, cultivation and differentiation of MSCs}

All experiments were carried out according to the guidelines for the care and use of experimental animals and approved by the State Veterinary Administration of the Czech Republic. General anesthesia of miniature pigs was induced by TKX mixture (Tiletamine $100 \mathrm{mg}$, Ketamine $10 \% 3 \mathrm{ml}$, Xylazine $2 \%$ $3 \mathrm{ml}$ ) in a dose of $1 \mathrm{ml}$ per $10 \mathrm{~kg}$ of body weight. Then we aspirated the bone marrow blood from tuber coxae ala osis ilii by bioptic needle $(15 \mathrm{G} / 70 \mathrm{~mm})$. The separation of mononuclear cells from whole bone marrow was performed by density gradient centrifugation at $400 \mathrm{~g}$ for $30 \mathrm{~min}$ at room temperature using Ficoll-PaqueTM PLUS (Stemcell Technologies; Canada). Mononuclear cells in an opalescent layer between Ficoll and blood plasma were collected, washed in a culture medium (see below) and used for propagation under in vitro conditions. The average amount of mononuclear cells was $50 \times 10^{6}$ cells per isolation. Cell count and viability were analyzed on Vi-CELL (Series $\times$ Cell Viability Analyzers) and about $98 \%$ of viable cells were detected. Cells were seeded in tissue culture flasks $\left(1.3 \times 10^{6} / \mathrm{cm}^{2}\right)$ and cultured at $37^{\circ} \mathrm{C}$ in $5 \% \mathrm{CO}_{2}$. The culture (control) medium was alphaMEM medium (GIBCO, Invitrogen) supplemented with $10 \%$ FBS (Sigma-Aldrich) and gentamycin $(50 \mathrm{mg} / \mathrm{ml}$; Sigma-Aldrich). After reaching $80 \%$ confluence the adherent MSCs were passaged using trypsin (0.5\% trypsin-EDTA solution; Sigma-Aldrich) and reseeded at a density of 15000 cells $/ \mathrm{cm}^{2}$. After 3rd passage the MSCs were harvested and analyzed for expression of surface markers $\mathrm{CD}^{29}, \mathrm{CD}^{44}, \mathrm{CD}^{45}, \mathrm{CD}^{90}, \mathrm{CD}^{105}$ and $\mathrm{CD}^{147}$ by flow cytometry. Defined MSCs were transferred into Petri dishes (Ø $40 \times 11 \mathrm{~mm}$ ), 6-well plates and 24-well plates coated with or without two extracellular matrix (ECM) molecules - vitronectin $\left(0.1 \mu \mathrm{g} / \mathrm{cm}^{2} ; 08-126\right.$; Millipore) and collagen I (10 $\mu \mathrm{g} / \mathrm{cm}^{2}$; C3867; Sigma) or embedded in PC and in PAC produced scaffolds (96-well plates). $100 \%$ confluent MSCs in monolayers and scaffolds were cultured in osteogenic medium containing $10 \mathrm{mM}$ glycerol 2-phosphate (50020; Fluka), $0.2 \mathrm{mM}$ L-ascorbic acid 2-phosphate (L-ascorbic acid 2-phosphate hydrate sesquimagnesium salt; A8960; Sigma) and $0.1 \mu \mathrm{M}$ dexamethasone (D4902, Sigma) or in control medium for three weeks. The plates and dishes were inspected in an Olympus IX70 Inverted fluorescence \& phase microscope and in Olympus CKX41 Inverted microscope, immunohistochemical preparations were viewed in an Olympus AX70 fluorescence microscope. The morphology and quantifying of MSCs growth on Petra dishes with or without coating of ECM molecules were also analyzed by IncuCyte ${ }^{\mathrm{TM}}$ Imaging System (Essen Bioscience, Inc., USA).

\section{Flow cytometry}

Harvested cells were washed in a blocking solution containing PBS supplemented with $10 \%$ FBS, $1 \%$ gelatin and $0.1 \%$ sodium azide. The cell suspension was adjusted to a concentration of $10 \times 10^{6}$ cells $/ \mathrm{ml}$ and incubated for $0.5 \mathrm{~h}$ at $4{ }^{\circ} \mathrm{C}$ with mouse anti-CD29 (clone MEM-101A), mouse anti-CD105 (clone MEM 229), or mouse anti-CD147 (clone MEM-M6/2), all three antibodies from Exbio Praha PLC., Prague, Czech Republic; rat anti-CD44 (clone IM7), mouse anti-CD90 (clone 5E10), both antibodies from BD Biosciences, San Jose, CA USA; mouse anti-CD45 (clone K252-1E4, AbD Serotec, Kidlington, UK ( $1 \mu \mathrm{g}$ antibody $/ 10^{6}$ cells $)$. The 
cells were washed three times by centrifugation at $350 \mathrm{~g}$ for $5 \mathrm{~min}$ and resuspending in ice-cold washing solution ( $1 \%$ gelatin/ $0.1 \%$ sodium azide/PBS). Alexa Fluor 488 conjugated secondary antibody diluted in blocking solution $(1: 1000)$ was applied for $30 \mathrm{~min}$ in the dark at $4{ }^{\circ} \mathrm{C}$. After incubation, cells were washed three times with ice-cold washing solution, resuspended in $1 \%$ gelatin $/ 0.1 \%$ sodium azide/PBS with propidium iodide for determination of supravitality of the cells and analyzed for the above antigens by using a Becton Dickinson FACSCalibur ${ }^{\mathrm{TM}}$ flow cytometer. Cytofluorimetric data were processed with CellQuest software (BD Biosciences). CD44 staining was performed with PE conjugated primary antibody using similar conditions and buffers as mentioned above. Antibodies with a matching isotype were used to detect nonspecific fluorescence.

\section{Preparation of scaffolds}

Miniature pig blood was collected into $3.8 \%$ buffered sodium citrate (S-4641; Sigma) and platelet containing plasma was separated by centrifugation and aspiration. Plasma clot (PC) and Plasma/alginate clot (PAC) scaffolds were prepared by re-suspending of 400000 MSCs in $30 \mu \mathrm{l}$ of $50 \%$ plasma and $50 \%$ plasma with $0.5 \%$ alginate (alginic acid sodium salt; A2158; Sigma) solution in PBS, respectively. Liquid cell suspension was then transferred to the bottom of a 96well plate and overlayered with complete medium supplemented with additional $5 \mathrm{mM} \mathrm{CaCl}{ }_{2}(\mathrm{C}-7902$; Sigma). Clotting was finished in 10 minutes and calcium was washed out by media change.

\section{Alizarin red staining}

Petri dishes with cells or cryo-sectioned scaffold sections were fixed by $70 \%$ ethanol for $1 \mathrm{~h}$ at room temperature. After complete washing with distilled water Alizarin Red Solution (2003999; Chemicon) was added to the dishes (without ECM molecules) and sections. After 30 minutes of incubation, the dishes and sections were washed four times with distilled water and inspected macro- and microscopically.

\section{Alkaline phosphatase activity \& DNA quantification}

Quantitative analysis of ALP activity was performed (6-well plates - with and without ECM proteins) by detecting the highly-fluorescent enzymatic product 4-methylumbelliferone (4-MU) that is produced by the enzymatic dephosphorylation of 4-methylumbelli- feryl phosphate (4-MUP, M8168, Sigma) at $80 \%$ and $100 \%$ confluence and after 7,14 and 21 days control and osteogenic cultivation $(\mathrm{n}=12-18)$. Monolayers were washed two times with PBS on ice. Then $200 \mu$ of lysis buffer (20 mM Tris-HCl, pH 7.5; $150 \mathrm{mM} \mathrm{NaCl} ; 1 \mathrm{mM}$ $\mathrm{Na}_{2}$ EDTA; 1 mM EGTA; $1 \%$ Triton X-100) was added to 1 well of the 6 -well plate. After 5 minutes the contents with lysis buffer were scraped off from the wells. The samples were then frozen and thawed three times combined with sonication and centrifuged at $12000 \mathrm{~g}$ for 2 min. The supernatants were removed and used for ALP and DNA quantification. Briefly, calf-intestine alkaline phosphatase (P4978, Sigma) standards in Tris/0.1 \% BSA buffer (pH 8.0) and samples (10 $\mu$ l) were put into 96-well black plates (Nunc ${ }^{\circledR}$ FluoroNunc ${ }^{\mathrm{TM}}$, P8741, Sigma). Then $50 \mu \mathrm{l}$ of $36 \mu \mathrm{M}$ 4-MUP solution in Tris/0.1 \% BSA buffer ( $\mathrm{pH}$ 8.0) was added to the wells, the plates were stirred and incubated in the dark at RT for $2 \mathrm{~min}$. The reaction was stopped by adding $190 \mu \mathrm{l} 0.2 \mathrm{M} \mathrm{Na}_{2} \mathrm{CO}_{3}$ (pH 12) and the fluorescence was immediately measured at $360 / 40 \mathrm{~nm}$ excitation and 460/40 nm emission on a Synergy HT Multi-Mode Microplate Reader (Biotek). The amount of alkaline phosphatase was calculated from the fluorescence measurement and the linear equation determined from the AP standard concentration vs. Fluorescence by Gen 5 data analysis software (Biotek).

DNA quantification was performed by a fluorescent assay. Activated calf thymus (D4522, Sigma) standards in fluorescent buffer (10 mM Tris-HCl, $\mathrm{pH} 7.4$; $1 \mathrm{mM}$ EDTA; $0.2 \mathrm{M} \mathrm{NaCl})$ and samples $(10 \mu \mathrm{l})$ were put into 96-well black plates Nunc $^{\circledR}$ FluoroNunc $^{\text {TM }}$, P8741, Sigma) and $200 \mu \mathrm{l}$ of $0.1 \mu \mathrm{g} / \mathrm{ml}$ bisbenzimide H33258 (14530, Sigma) in fluorescent buffer was added. The fluorescence was immediately measured at $360 / 40 \mathrm{~nm}$ excitation and 460/40 nm emission on the Synergy HT Multi-Mode Microplate Reader (Biotek). The amount of DNA was calculated from the fluorescence measurement and the linear equation determined from the DNA standard concentration vs. Fluorescence by Gen 5 data analysis software (Biotek).

The Student t-test was used for determining the significance of the ALP/DNA ratios $(\mathrm{mIU} / \mu \mathrm{g})$. The results were expressed as mean values \pm S.D. and values of $p<0.05$ were considered significant.

\section{Immunohistochemistry}

After 0, 7, 14 and 21 days the PC scaffolds and monolayers (without ECM molecules) were fixed in $4 \%$ paraformaldehyde and the PC scaffolds were prepared for 
cryo-sectioning in $30 \%$ sucrose. Hematoxylin-eosin staining was used for cryo-sections only. Sections $(10 \mu \mathrm{m})$ and monolayers were successively treated with $1 \%$ bovine serum albumin (Albumin bovine fraction V; pH 5.2; 11922; Serva) and $0.4 \%$ Triton ${ }^{\circledR}$ X-100 (T8532, Sigma) in PBS for $1.15 \mathrm{~h}$ at RT, primary antibodies (rabbit polyclonal to osteopontin, ab8448, ABCAM, 1:250; mouse monoclonal to osteocalcin, ab13418, ABCAM, 1:100; mouse monoclonal to osteonectin,
AON-1, DSHB, University of Iowa, Iowa City, IA, $1: 1000$ ) in $1 \% \mathrm{BSA} / 0.4 \%$ Triton ${ }^{\circledR} \mathrm{X}-100 / \mathrm{PBS}$ overnight $\left(4{ }^{\circ} \mathrm{C}\right)$, secondary antibodies (Alexa Fluor ${ }^{\circledR} 555$ goat anti-rabbit IgG, Invitrogen, 1:500; Alexa Fluor ${ }^{\circledR} 555$ goat anti-mouse $\mathrm{IgG}$, Invitrogen, 1:500) in $1 \% \mathrm{BSA} / 0.4 \%$ Triton-X/PBS for $1.5 \mathrm{~h}$ at RT, and 4',6-diamidino-2phenylindole diluted 1:500 in PBS for $10 \mathrm{~min}$ at RT and mounted.
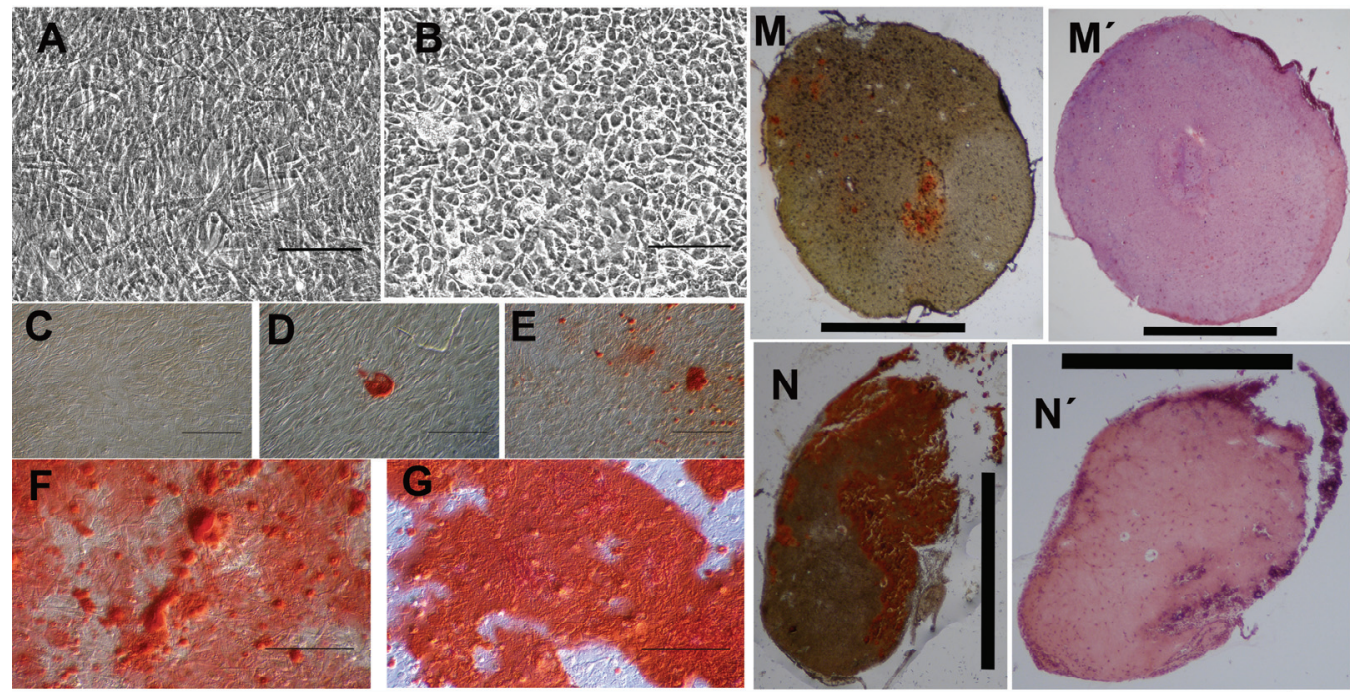

H

All Sectors Mean vs Time

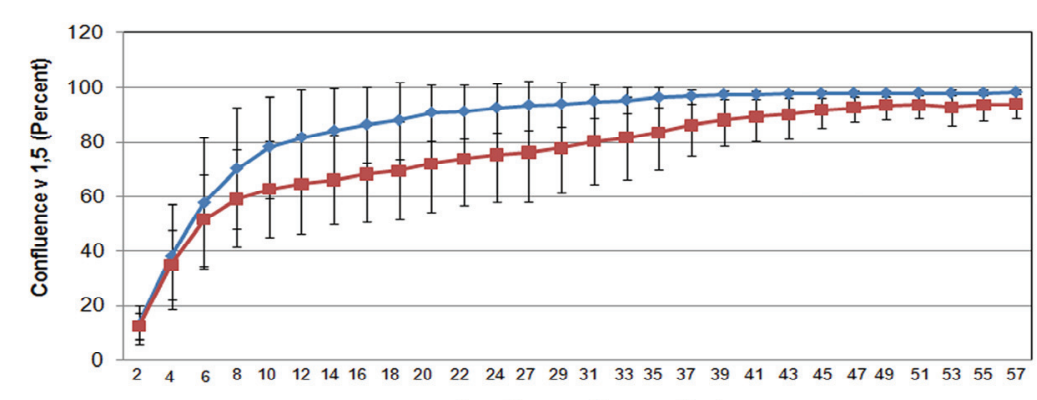

time (hours after seeding)
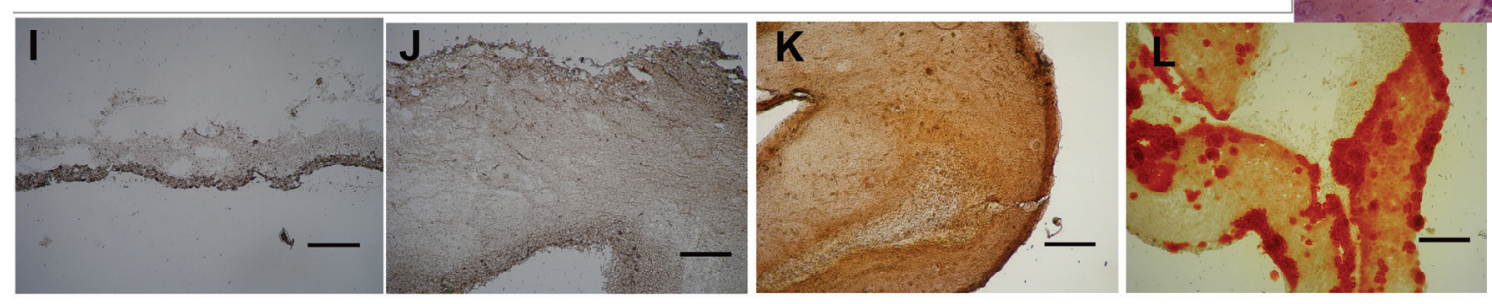

Fig. 1. Micrographs of MSCs after 3 weeks of differentiation on tissue plastic coated with collagen I and vitronectin. Cells cultured in nonosteogenic growth medium maintained a spindle-like shape (A). In contrast, MSCs cultivated in osteogenic medium changed their phenotype from spindle-shaped cells to more cuboidal-shaped cells (B). Micrographs of monolayers (without ECM coating) stained with Alizarin Red stain after 7 (D), 10 (E), 14 (F) and 21 (G) days of osteogenic differentiation or 14 days (C) of control cultivation. The confluence of miniature pig MSCs growing on the ECM coated wells in comparison with uncoated wells during first $57 \mathrm{~h}$ after seeding that was evaluated by IncuCyte software $(\mathbf{H})$. Micrographs of Alizarin Red stained plasma clot scaffold seeded with MSCs at the start (I) and after 7 (J), 14 (K) and 21 (L) days of osteogenic differentiation. Scale bar (A-G; I-L) $200 \mu \mathrm{m}$. Micrographs of Alizarin Red stained (M) and hematoxylin-eosin stained (M', $\left.\mathbf{M}^{\prime \prime}\right)$ plasma/alginate clot scaffold seeded with MSCs on the $21^{\text {th }}$ day of osteogenic differentiation. Micrographs of Alizarin Red stained $(\mathbf{N})$ and hematoxylin-eosin stained $\left(\mathbf{N}^{\prime}, \mathbf{N}^{\prime \prime}\right.$ ) plasma clot scaffold seeded with MSCs on the $21^{\text {th }}$ day of osteogenic differentiation. Photos of plasma/alginate scaffolds ( $\left.\mathbf{M}^{\prime \prime \prime}\right)$ and plasma scaffolds $\left(\mathbf{N}^{\prime \prime}\right.$ ) on the chart paper. Scale bar $\left(M, M^{\prime}, N, N^{\prime}\right) 1000 \mu \mathrm{m}$ and $\left(M^{\prime \prime}, N^{\prime \prime}\right) 50 \mu \mathrm{m}$. 


\section{Western blot}

Miniature pig MSCs (ECM coated/uncoated dishes) and MSC-seeded PC scaffolds were lysed for 30 minutes using lysis buffer containing $50 \mathrm{mM}$ Tris $(\mathrm{pH}$ 7.4) (5429.3; Roth), $250 \mathrm{mM} \mathrm{NaCl}$ (3957.2; Roth), $5 \mathrm{mM}$ EDTA (E5134; Sigma), 50 mM NaF (S-1504; Sigma), $1 \mathrm{mM} \mathrm{Na} \mathrm{VO}_{4}$ (S6508; Sigma) in $1 \%$ Triton ${ }^{\circledR}$ X-100 (T8532; Sigma) with protease inhibitor cocktail tablets (Complete Mini, EDTA-free; 11836170001; Roche) and $1 \mathrm{mM}$ phenylmethylsulphonyl fluoride (PMSF; 837091; Roche). Sonication of all samples was performed in cold water bath for 5 minutes and was followed by centrifugation at $10000 \mathrm{~g}$ at $4{ }^{\circ} \mathrm{C}$ for $20 \mathrm{~min}$. Total protein levels were determined by BCA Protein Assay Kit (\#23225, ThermoScientific) and $15 \mu \mathrm{g}$ of each sample was loaded on $10 \%$ polyacrylamide gels together with sample buffer (125 mM Tris-HCl, $4 \%$ SDS, $20 \%$ glycerol, $10 \%$ 2-mercaptoethanol, $0.004 \%$ bromophenol blue) and distilled water. After polyacrylamide gel electrophoresis the proteins were transferred to nitrocellulose membranes using a semidry blotting system. The membranes were blocked with $5 \%$ nonfat dry milk (NFDM) in tris-buffered saline with $0.5 \%$ Tween 20 (TBS-T) and incubated with the primary antibodies (rabbit polyclonal to osteopontin, ab8448, ABCAM, 1:1000; mouse monoclonal to osteocalcin, ab13418, ABCAM, 1:1000; mouse monoclonal to osteonectin, AON-1, DSHB, University of Iowa, Iowa City, IA, 1:1000) in $5 \%$ NFDM in TBS-T overnight on a roller at $4{ }^{\circ} \mathrm{C}$. After washing with TBS-T buffer the membranes was incubated with Peroxidase-conjugated AffiniPure Goat Anti-Rabbit IgG (Jackson ImmunoResearch Laboratories, Inc.) diluted 1:35 000 or Peroxidase-conjugated AffiniPure Donkey Anti-Mouse IgG (Jackson ImmunoResearch Laboratories, Inc.) diluted 1:10 000 in 5\% NFDM in TBS-T for 1 hour at RT with gentle shaking. SuperSignal West Pico Chemiluminescent Substrate (34077, Pierce) detection system was used for visualization. Western blotting signal was quantified by determining the grey values of given bands using the ImageJ software.

\section{Results}

\section{Flow cytometry}

Flow cytometric analysis revealed strong positivity of cells for mesenchymal cell markers $\mathrm{CD}^{29}$ (98.40\%) and for $\mathrm{CD}^{90}(98.87 \%)$. We observed also massive positivity for $\mathrm{CD}^{44}(97.78 \%)$ and $\mathrm{CD}^{147}$
(96.60\%). Mild positivity was detected for $\mathrm{CD}^{105}$ $(55.99 \%)$ and no positivity was evaluated for common leukocyte antigen $\mathrm{CD}^{45}(0.05 \%)$.

\section{Cultivation and osteogenic differentiation}

Miniature pig MSCs showed fibroblastic morphology within approximately 2 weeks of 2D environment cultivation in osteogenic medium (Fig. 1A). After 3 weeks of osteogenic differentiation the cells changed their morphology from spindle-shaped to cuboid and formed aggregates and large nodules missing in control cultivation (Fig. 1B). The $98 \%$ confluence of MSCs $(n=36)$ in dishes coated with vitronectin and collagen I was achieved more quickly $(57 \mathrm{~h})$ after seeding compared to MSCs $(n=36)$ in dishes without these molecules $(89 \mathrm{~h})$. The significant difference between confluence of miniature pig MSCs with or without ECM molecules was already detected in $8 \mathrm{~h}(70.34 \pm 22.27$ vs. $59.29 \pm 17.97)$ and lasted till $97 \mathrm{~h}$ of cultivation (98.60 \pm 0.19 vs. $98.17 \pm 0.40$ ) (Fig. 1H). Moreover, we also measured $10.67 \pm 0.44 \mu \mathrm{g} / \mathrm{ml}$ DNA from MSCs growing on the ECM uncoated wells $(n=12)$ and just $10.20 \pm 0.59 \mu \mathrm{g} / \mathrm{ml}$ from MSCs seeded on vitronectin and collagen I coated wells $(n=12) 22 \mathrm{~h}$ after seeding (approximately $80 \%$ confluence of cells). Therefore we suggest that significantly higher confluence of MSCs cultivated on our combination of ECM molecules were not caused neither higher amount of adherent cells nor better cell proliferation during first hours after seeding but different cell adhesion and different morphology of MSCs after adhesion to the vitronectin/collagen I combination. The MSCs on ECM molecules possessed more polygonal shape in contrast to more spindle shape of MSCs on uncoated plastic after their seeding that resulted into the higher confluence. Cells dispersed in plasma or plasma/alginate mixture were embedded in gel like clot in the presence of calcium ions within 10 minutes. Complete plasma clot (PC) scaffold contraction was observed within 3 days. Plasma/alginate clot (PAC) scaffold contracted slightly and folded gradually through 2 weeks. Plasma scaffold contraction was partially reduced by addition of alginate (Fig. $1 \mathrm{M}^{\prime \prime}$, $\left.1 \mathrm{~N}^{\prime \prime}\right)$. Resulting clots were stable for at least 3 weeks at in vitro conditions and could be then easily manipulated without the risk of crushing. PC and PAC scaffolds in control cultivation were less compact and more fragile than differentiated groups during section processing. The main disadvantage of PC and PAC seeded scaffolds is that their newly produced extracellular matrix was 
located mainly at periphery and the centrally embedded MSCs during cultivation or differentiation weren't active.

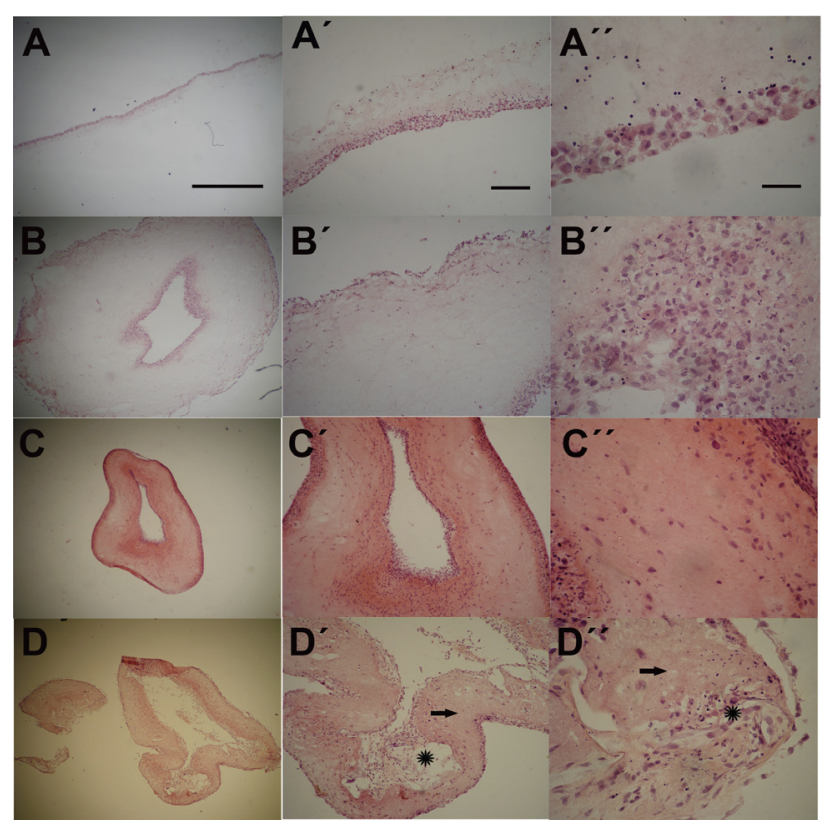

Fig. 2. Micrographs of hematoxylin-eosin stained plasma clot scaffolds seeded with MSCs at the start $\left(\mathbf{A}, \mathbf{A}^{\prime}, \mathbf{A}^{\prime \prime}\right)$ and after 7 (B, B', B' '), $14\left(\mathbf{C}, \mathbf{C}^{\prime}, \mathbf{C}^{\prime \prime}\right)$ and 21 (D, D', $\left.\mathbf{D}^{\prime \prime}\right)$ days of osteogenic differentiation. Arrows indicate a plasma clot scaffold and stars indicate a newly created ECM. Scale bar (A, B, C, D) $1000 \mu \mathrm{m},\left(A^{\prime}, B^{\prime}, C^{\prime}, D^{\prime}\right) 200 \mu \mathrm{m}$ and $\left(A^{\prime \prime}, B^{\prime \prime}, C^{\prime \prime}, D^{\prime \prime}\right)$ $50 \mu \mathrm{m}$.

\section{Alizarin red staining and hematoxylin-eosin}

Approximately 7 days after osteogenic differentiation in 2D environment (ECM coated/uncoated dishes) the cells started to produce only microscopically visible depositions of calcium (Fig. 1D, E, F, G). Macroand micro-visible depositions of calcium were observed on the $10^{\text {th }}$ day of differentiation (Fig. 1E). Cells without osteogenic medium did not produce calcium depositions even after 14-day cultivation (Fig. 1C). PAC scaffolds showed uneven distribution of cells in the scaffold due to slow hardening of scaffold at the beginning of the cultivation and partial sedimentation of cells (Fig. $1 \mathrm{M}$, $\left.\mathrm{M}^{\prime}, \mathrm{M}^{\prime \prime}\right)$. In addition, PAC scaffolds developed a pseudo cavity during contraction (Fig. $1 \mathrm{M}^{\prime \prime}$ ). In contrast, PC scaffolds produced a compact structure during contraction and full sedimentation of miniature pig MSCs was observed (Fig. 2A-A'). PC and PAC scaffolds seeded with cells and cultivated three weeks in osteogenic medium supported the formation of compact pellets in contrast to control medium cultivation. During control cultivation, PC and PAC scaffolds were gradually fragmented. In addition, at the end of osteogenic differentiation Alizarin red staining and H\&E staining revealed stronger production of ECM and formation of calcium depositions in PC scaffolds compared with PAC scaffolds (only sparse foci) (Fig. $1 \mathrm{~N}, \mathrm{~N}^{\prime}, \mathrm{N}^{\prime \prime}$ ). Because of the better histological outcomes of PC scaffolds during differentiation we repeated osteogenic cultivation of these scaffolds again. Disc-shaped PC scaffolds with MSCs sediment at the time of scaffold formation were changed into dish-shaped scaffolds with peripherally distributed MSCs after 7 days of differentiation (Fig. 2A, B). At the same time we observed also multiplication of seeded MSCs and their degradation of PC scaffolds. Moreover, the MSCs were observed to start new formation of ECM. During the next two weeks of differentiation MSCs continued in the infiltration of PC scaffolds and in the production of their ECM. We also observed the formation of hematoxylin-stained calcium granules confirmed by Alizarin red staining (Fig. 1L, 2C, 2D).

\section{ALP/DNA ratio}

As expected, the ALP/DNA (mIU/ $\mu \mathrm{g})$ ratios of $80 \%$ confluent MSCs (22 h after seeding) growing on coated or uncoated wells were significantly lower in comparison with $100 \%$ confluent cells (43 h after seeding) but the difference was higher on uncoated $(\mathrm{p}<0.001)$ than coated $(\mathrm{p}<0.01)$. However, the ALP/DNA ratios were comparable between $80 \%$ confluent MSCs on coated and uncoated plastic $(\mathrm{p}=0.370)$. Moreover the DNA content of MSCs in uncoated wells was significantly higher compared to the MSCs growing on coated ones $(p<0.05)$ at this time point. Surprisingly we observed significantly higher ALP/DNA ratio of $100 \%$ MSCs proliferating on uncoated than coated wells $(\mathrm{p}<0.01)$. On the other hand DNA content was comparable between these cells (Table 1; $\mathrm{p}=0.111$ ). Clearly increase of ALP activity was occurred in MSCs by osteogenic stimuli but the difference between cells growing on coated and uncoated plastic wasn't significant on $7^{\text {th }}(\mathrm{p}=0.124)$ and $14^{\text {th }}(\mathrm{p}=0.281)$ day. Surprisingly the significantly higher ALP/DNA ratios in MSCs from uncoated wells compared to ECM coated wells we observed on day 21 of osteogenic differentiation $(\mathrm{p}<0.001)$. The $7^{\text {th }}$ day of osteogenic cultivation is the only time point in which the DNA content of monolayers on ECM coated wells was significantly higher than DNA content on uncoated ones (Table $1 ; \mathrm{p}<0.05$ ). Important is that in the presence of osteogenic medium a maximum ALP activity was reached after three weeks both in MSCs on coated and uncoated plastic. On the other hand in 
Table 1. ALP/DNA (mIU/ $\mu \mathrm{g})$ ratio and DNA $(\mu \mathrm{g} / \mathrm{ml})$ content in miniature pig MSCs during $2 \mathrm{D}$ cultivation in control and osteogenic medium (with or without ECM molecules coating).

\begin{tabular}{|c|c|c|c|c|c|}
\hline & $80 \%$ confluence & $\begin{array}{c}100 \% \text { confluence } \\
\text { (Day 0) }\end{array}$ & Day 7 & Day 14 & Day 21 \\
\hline \multirow[t]{2}{*}{ Control medium } & $0.08 \pm 0.03$ & $0.16 \pm 0.02^{\mathrm{a}}$ & $0.12 \pm 0.03$ & $0.61 \pm 0.11$ & $0.25 \pm 0.07^{\mathrm{a}}$ \\
\hline & $10.67 \pm 0.44^{a}$ & $10.03 \pm 0.40$ & $11.94 \pm 0.51^{a}$ & $12.28 \pm 0.76$ & $12.20 \pm 1.04^{a}$ \\
\hline \multirow{2}{*}{$\begin{array}{l}\text { Osteogenic } \\
\text { medium }\end{array}$} & - & - & $0.99 \pm 0.22$ & $2.51 \pm 0.66$ & $7.50 \pm 1.07^{\mathrm{a}}$ \\
\hline & - & - & $10.70 \pm 0.95$ & $12.68 \pm 0.63^{a}$ & $11.25 \pm 1.16^{a}$ \\
\hline \multirow{2}{*}{$\begin{array}{l}\text { Control medium } \\
+E C M\end{array}$} & $0.09 \pm 0.03$ & $0.13 \pm 0.03$ & $0.28 \pm 0.06^{\mathrm{a}}$ & $0.66 \pm 0.07$ & $0.19 \pm 0.04^{b}$ \\
\hline & $10.20 \pm 0.59$ & $10.24 \pm 0.42$ & $10.82 \pm 0.77$ & $11.93 \pm 0.40$ & $11.35 \pm 0.65^{b}$ \\
\hline \multirow{2}{*}{$\begin{array}{l}\text { Osteogenic } \\
\text { medium }+ \text { ECM }\end{array}$} & - & - & $1.15 \pm 0.40$ & $2.36 \pm 0.73$ & $5.36 \pm 1.40$ \\
\hline & - & - & $11.48 \pm 0.64^{a}$ & $10.48 \pm 0.50$ & $9.71 \pm 0.99$ \\
\hline
\end{tabular}

Values are arithmetical means \pm SD. Statistical differences (t-test): ${ }^{a}$ ECM uncoated vs. ECM coated wells with the same medium and at same time point. ${ }^{\mathrm{b}}$ All analyzed wells were stripped.

control cultivation we detected a culmination of ALP activity in MSCs (coated/uncoated wells) on $14^{\text {th }}$ day. As we expected there were significantly higher ALP/DNA ratios in MSCs growing on vitronectin/collagen I mixture in comparison with uncoated wells on $7^{\text {th }}$ day of control cultivation. After three weeks of control cultivation was observed decrease of ALP activity in MSCs (coated/uncoated plastic). We indeed found out significantly lower ALP/DNA ratios $(p<0.01)$ in MSCs of coated wells compared to uncoated wells on $21^{\text {th }}$ day in control cultivation but it was probably caused by the stripping of monolayers in all coated wells (Table 1).

\section{Immunohistochemistry}

Since PC scaffolds seemed to produce better outcomes in comparison with PAC scaffolds, we used PC scaffolds for further detection of osteogenic markers (osteopontin, osteonectin and osteocalcin) by immunohistochemistry. These markers were also assayed in a 2D environment without ECM molecules. We did not detect osteocalcin either in monolayers or PC scaffolds by immunohistochemistry at the beginning of osteogenic differentiation and entire control cultivation. Osteocalcin started to be observed in 2D environment on $7^{\text {th }}$ day of osteogenic differentiation when a few osteocalcin positive cells were detected. In contrast, osteocalcin expression in PC scaffolds was first immunostained on $14^{\text {th }}$ day. In Petri dishes and plates without ECM molecules, osteocalcin reached a maximum after three weeks of differentiation. Low expression of osteonectin was observed in PC scaffolds and Petri dishes at the beginning of osteogenic differentiation and during the whole control cultivation. It reached a higher level after one week of 2D and 3D differentiation and persisted until the final collection. The osteonectin expression in MSCs on uncoated dishes after two weeks of differentiation increased in comparison with 1-week differentiation but declined at the end of differentiation. We already detected a high expression of osteopontin at the time of formation of PC scaffolds and $100 \%$ confluence of MSCs in control medium. Osteopontin was present during both osteogenic differentiation and control cultivation but the expression signal was more intensive in osteogenic medium. After 7 days of differentiation in monolayers and after 21 days of differentiation in PC scaffolds we observed a decrease of osteopontin level. After possible stripping of monolayers and the creation of villi the reseeded MSCs showed again a high osteopontin signal. In contrast, osteopontin expression in the confluent parts of re-seeded dishes decreased (Fig. 3).

\section{Western blot}

By using Western blot analysis we were unable to detect any of the three osteogenic markers in PC scaffolds during differentiation. This fact was caused by the paucity of cells and cell-produced markers 


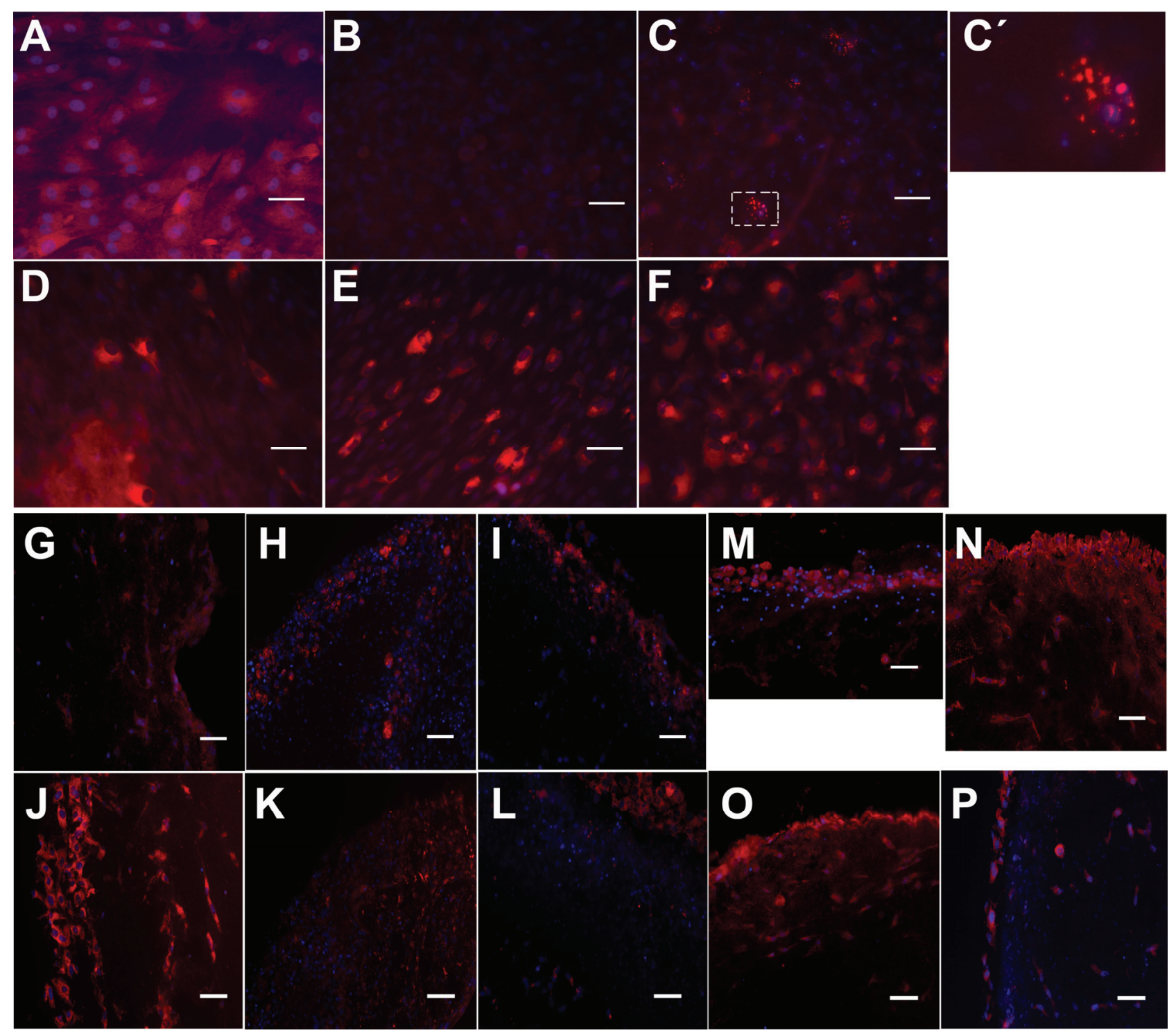

Fig. 3. Osteopontin and DAPI double immunostaining of monolayers at the start (A) and after three weeks (B) of osteogenic differentiation. Osteonectin and DAPI double immunostaining of monolayer after 14 days (C) of osteogenic differentiation (C' detail). Osteocalcin and DAPI immunostaining of monolayers (D, E, F) or plasma clot seeded scaffolds $(\mathbf{G}, \mathbf{H}, \mathbf{I})$ after $7(\mathrm{D}, \mathrm{G}), 14(\mathrm{E}, \mathrm{H})$, and $21(\mathrm{~F}, \mathrm{I})$ days of osteogenic differentiation. Osteonectin and DAPI double immunostaining of plasma clot scaffolds seeded with MSCs after $7(\mathbf{J}), 14(\mathbf{K})$, and $21(\mathbf{L})$ days of osteogenic differentiation. Osteopontin and DAPI double immunostaining of plasma clot seeded scaffolds at the start (M) and after $7(\mathbf{N}), 14(\mathbf{O})$, and $21(\mathbf{P})$ days of osteogenic differentiation. Scale bar $50 \mu \mathrm{m}$.

in the samples. In spite of the fact that osteocalcin antibody worked very well when using immunohistochemistry we were not able to determine osteocalcin in monolayers. We explain this fact by the low concentration of osteocalcin in loaded sample because the recommended loading amount of osteocalcin should be $10 \mu \mathrm{g}$. Western blot revealed the expression of osteonectin in Petri dishes with ECM as well as without ECM during the whole osteogenic differentiation. Miniature pig MSCs growing on Petri dishes without ECM produced a minimal amount of osteonectin at the start of differentiation whereas a rapid increase of osteonectin expression was observed on $7^{\text {th }}$ day of differentiation. The increase of osteonectin production culminated two weeks after the addition of osteogenic medium. At the end of differentiation the osteonectin expression slowly decreased and achieved the level of approximately one-week differentiation. The expression of osteonectin in MSCs differentiated with ECM mimicked also the total curvature but the culmination of osteonectin was present on $7^{\text {th }}$ day of differentiation. Moreover, ECM coated dishes revealed a higher starting and lower final expression of osteonectin than uncoated ones. In MSCs differentiated on ECM coated/uncoated dishes we detected $66 \mathrm{kDa}$ and $32 \mathrm{kDa}$ bands that correspond to osteopontin. There were also more 
additional bands with higher molecular weight $(>66 \mathrm{kDa})$ that should not agree with osteopontin. The strongest osteopontin expression observed at the beginning of osteogenic differentiation in coated as well as uncoated dishes seeded with miniature pig MSCs slowly decreased during differentiation in monolayers cultivated with or without ECM. The amounts of osteopontin in MSCs seeded dishes without collagen I and vitronectin were higher than those in ECM-coated dishes. After three weeks of differentiation. The lowest visible osteopontin signal was detected in ECM uncoated dishes (Fig. 4).

\section{Discussion}

There are several studies characterizing pig MSCs isolation, cultivation and differentiation in vitro (Bosch et al. 2006, Qu et al. 2007, Ringe et al. 2002). Our study extended the information relating to the osteogenic potential of miniature pig MSCs and compared the porcine MSCs osteogenic differentiation in $2 \mathrm{D}$ environment and two types of scaffolds and focused on the expression of osteogenic markers. We decided for the plasma clot and plasma-alginate clot scaffolds because there are many scientific papers that declare alginate and fibrin are useful for MSCs scaffold generation (Yildirim et al., 2010, Kang et al., 2010, Nakamura et al., 2010, Suárez-González et al., 2010, Trombi et al., 2008) and we wanted to imitate the fate of MSCs after their embedding into the scaffolds followed by in vitro osteogenic differentiation before transplantation into the miniature pigs. We also want to create a simple-formed autologous scaffold supporting osteogenic differentiation while avoiding possible infection transfer or donor graft rejection. Since bone cells purportedly originate from mesenchymal stem cells that belong to the osteogenic cell lineage that yields osteoprogenitor cells, preosteoblasts, osteoblasts, and osteocytes, understanding of this developmental process requires an observation of lineage-specific markers and their expression during cultivation (Long 2001). The TNAP (tissue non-specific alkaline phosphatase) is the predominant bone paralog of ALP that is expressed on the plasma membrane of osteoblasts and osteoblast precursors, on bone lining cells, and on matrix vesicles, the initial site of mineralization (Kaunitz and Yamaguchi 2008). We therefore decided to detect the most frequently mentioned osteogenic markers, namely osteocalcin, osteonectin, osteopontin and ALP (TNAP) activity. Some discrepancy occurred between the

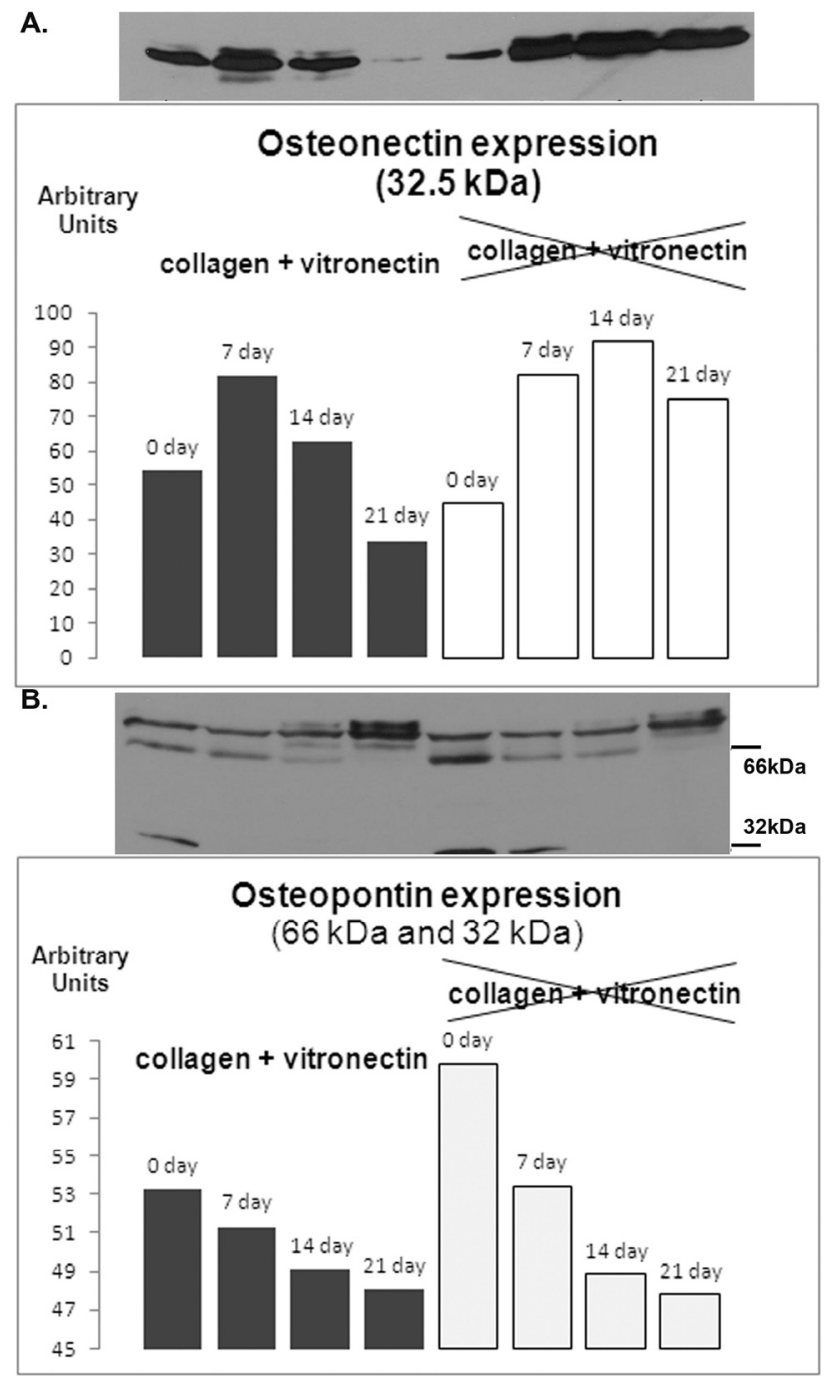

Fig. 4. Densitometric assessment in arbitrary units and representative images of (A) the osteonectin and (B) osteopontin expression in miniature pig MSCs osteo-differentiated on collagen I/vitronectin coated or uncoated dishes for three weeks.

immunohistochemistry results in PC scaffolds and monolayers during differentiation and cultivation. Our results showed that osteocalcin was detected only immunohistochemically and its production was not present at the beginning of osteogenic differentiation and during whole control cultivation. Moreover we were not able to detect osteocalcin expression in monolayers before $7^{\text {th }}$ day and in PC scaffolds before $14^{\text {th }}$ day of differentiation. These results correlate with other studies which showed that osteocalcin gene was induced up to 39 -fold on $12^{\text {th }}$ day in osteogenic cultures of porcine MSCs compared with non-osteogenic controls (Ringe et al. 2002) or was observed in porcine adipose mesenchymal stem cells on the $14^{\text {th }}$ day of osteogenic differentiation (Qu et al. 2007). Similarly, human MSCs 
differentiated for 14 days in osteogenic medium exhibited a significantly higher expression of osteocalcin gene as well as ALP activity than control MSCs (Wang et al. 2009). On the other hand, osteonectin gene was only marginally induced during differentiation in pig MSCs (Ringe et al. 2002). By immunostaining of PC scaffolds and Petri dishes (without ECM molecules) seeded with MSCs and cultivated with osteogenic and control medium we also revealed a small contrast in osteonectin expression during differentiation or cultivation. Moreover, our Western Blot analysis detected osteonectin expression during the whole osteo-cultivation with a maximum on the $7^{\text {th }}$ (ECM coated dishes) or $14^{\text {th }}(\mathrm{ECM}$ uncoated dishes) day of differentiation. There is evidence that contact with vitronectin and collagen I promotes the osteogenic differentiation of hMSC, and that ECM contact may be sufficient to induce differentiation in these cells (Salasznyk et al. 2004, Liu et al. 2004, Datta et al. 2005). By using this methodology we found out specific differences in the expression of osteogenic markers in MSCs differentiated on uncoated and coated dishes. At the beginning of the differentiation (after $100 \%$ confluence of cells) there was approximately a two-fold increase of osteonectin and osteopontin expression in MSCs growing on ECM coated dishes in comparison with uncoated dishes. This result was probably in accordance with the above-mentioned study. We hypothesized that, even without osteogenic medium, miniature pig MSCs seeded on ECM coated dishes likewise started differentiating during proliferation in control medium already before reaching the total confluence and thereafter. This speculation was supported by osteonectin peak in MSCs growing on vitronectin and collagen I coated dishes on $7^{\text {th }}$ day of osteogenic differentiation while the maximum of osteonectin expression in miniature pig MSCs seeded on uncoated dishes we detected one week later. The Western blot revealed a sheer drop of osteonectin production in MSCs cultivated on ECM coated dishes at the end of differentiation. In addition there was still a high expression of osteonectin in MSCs without ECM molecules after three weeks of differentiation. Our hypothesis could also be supported by ALP/DNA ratio results in coated and uncoated wells. After one week of control cultivation we observed more than 2-fold increase in ALP/DNA ratios in vitronectin/collagen coated wells compared to uncoated ones. Similarly we may only speculate that the higher ALP/DNA ratio in uncoated wells on $21^{\text {th }}$ day of osteogenic differentiation was caused by later ALP activity peak in these wells compared to ECM coated ones. The time course of osteopontin expression in differentiated MSCs with or without ECM molecules also supported the results of osteonectin detection. There is evidence that the level of osteopontin protein or its gene expression was increased during osteogenic differentiation of MSCs or MSCs-like cells (Valenti et al. 2008, Temenoff et al. 2004, Shin et al. 2004). Surprisingly, by using Western blot analysis we observed a consistent decrease of both osteopontin forms during osteogenic differentiation, whether in MSCs cultivated on vitronectin and collagen I or without these molecules. A similar osteopontin decline was also detected in monolayers and plasma cloth scaffolds by immunohistochemistry during osteodifferentiation or cultivation. Our osteopontin related findings are in agreement with the results of other studies and also with osteopontin interaction with $\mathrm{CD}^{44}$ cell-surface glycoprotein that was present in our cells. Potier et al. (2007) evaluated the expression of osteopontin and other osteoblastic markers in human MSCs by RT-PCR analysis and found a maximum osteopontin expression at the beginning of the osteodifferentiation (with or without hypoxia) and a decline in the expression during four weeks of differentiation. Similarly Romero-Prado et al. (2006) observed a decline of osteopontin gene expression in human MSCs after one week of differentiation. Osteopontin gene expression in human MSCs seeded on polystyrene and 50-500 nm collagen I nanofibers was also found to decrease after three weeks in comparison with two weeks in osteogenic medium (Shih et al. 2006). Accordingly, we suppose that MSCs seeded on ECM coated dishes started differentiating already without osteogenic stimuli and before reaching confluence. Moreover, osteonectin and osteopontin monitoring indicates faster formation as well as termination of the differentiation process in MSCs cultivated on ECM molecules. In addition, our recorded change of MSCs morphology on the vitronectin/collagen mixture was in accordance with other study (Engler et al. 2006). The morphology modification of MSCs from spindle shape to polygonal on ECM coated plastic could explain the significantly lower amount of DNA content in these wells in several time points of control cultivation (80\% confluence, $7^{\text {th }}$ and $21^{\text {th }}$ day) and osteogenic differentiation $\left(14^{\text {th }}\right.$ and $21^{\text {th }}$ day). We also detected ALP activity peak on $14^{\text {th }}$ day of control cultivation and the highest ALP activity after three weeks of osteogenic differentiation (coated/uncoated wells). This increment of 
ALP activity during two weeks of differentiation looks like the time course of ALP activity in human MSCs differentiated on polystyrene or collagen I nanofibers (Shih et al. 2006). In addition, we observed almost 30fold difference between MSCs cultivated in osteogenic and control medium after three weeks (coated and uncoated plastic). Our maximum of ALP activity was in accordance with ALP activity detected after three weeks in the study of Zou et al. (2007) who also observed a decrease of ALP gene expression on $21^{\text {th }}$ day of differentiation relative to that on $14^{\text {th }}$ day. It should be noted that the time-course of osteonectin and osteocalcin gene expression in this study looked-like osteonectin and osteocalcin expression in our experiments evaluated by immunodetection.

In conclusion, PC scaffolds provided better opportunities for MSCs osteodifferentiation in comparison with PAC scaffolds in static culture but they were not ideal. PC scaffolds enabled differentiation of porcine MSCs predominantly at the periphery. On the same day ( $7^{\text {th }}$ day of differentiation) we detected an osteonectin peak in PC scaffolds and monolayers with ECM molecules that could indicate similar differentiation properties of both cultivation systems. Anyhow, the results of our PC and PAC scaffolds as the MSCs carriers were dubious because the weak proliferation and differentiation of MSCs in the central part of scaffolds was occurred. This result was probably caused by the missing connection and communication between MSCs in PAC scaffolds and sedimentation of MSCs in PC scaffolds immediately after their generation. Finally, our results on ALP activity, deposition of calcium and osteogenic markers indicate that the optimal time for transplantation of in vitro differentiated cells and/or scaffolds (static system) into miniature pig bone defects varies between 10-21 days.

\section{Conflict of Interest}

There is no conflict of interest.

\section{Acknowledgements}

We express our thanks to Patricia Jandurova and Václav Pech for their excellent assistance in the immunocytochemical and histological analyses. The study was supported by the Academy of Sciences of the Czech Republic (Institutional research plan AV0Z50450515) and Ministry of Education, Youth and Sports of the Czech Republic (Projects 1M0538 and 2B06130).

\section{References}

ABBAH SA, LU WW, CHAN D, CHEUNG KM, LIU WG, ZHAO F, LI ZY, LEONG JC, LUK KD: Osteogenic behavior of alginate encapsulated bone marrow stromal cells: an in vitro study. J Mater Sci Mater Med 19: 2113-2119, 2008.

BODDE EW, WOLKE JG, KOWALSKI RS, JANSEN JA: Bone regeneration of porous beta-tricalcium phosphate (Conduit TCP) and of biphasic calcium phosphate ceramic (Biosel) in trabecular defects in sheep. $J$ Biomed Mater Res A 82: 711-722, 2007.

BOSCH P, PRATT SL, STICE SL: Isolation, characterization, gene modification, and nuclear reprogramming of porcine mesenchymal stem cells. Biol Reprod 74: 46-57, 2006.

CHANG SH, HSU YM, WANG YJ, TSAO YP, TUNG KY, WANG TY: Fabrication of pre-determined shape of bone segment with collagen-hydroxyapatite scaffold and autogenous platelet-rich plasma. J Mater Sci Mater Med 20: 23-31, 2009.

DATTA N, HOLTORF HL, SIKAVITSAS VI, JANSEN JA, MIKOS AG: Effect of bone extracellular matrix synthesized in vitro on the osteoblastic differentiation of marrow stromal cells. Biomaterials 26: 971-977, 2005.

ENGLER AJ, SEN S, SWEENEY HL, DISCHER DE: Matrix elasticity directs stem cell lineage specification. Cell 126: 677-689, 2006.

GÁl P, NEČAS A, PLÁNKA L, KECOVÁ H, KŘEN L, KRUPA P, HLUČILOVÁ J, USVALD D: Chondrocytic potential of allogenic mesenchymal stem cells transplanted without immunosuppression to regenerate physeal defect in rabbits. Acta Vet Brno 76: 265-275, 2007. 
HAUTAMÄKI MP, AHO AJ, ALANDER P, REKOLA J, GUNN J, STRANDBERG N, VALLITTU PK: Repair of bone segment defects with surface porous fiber-reinforced polymethyl methacrylate (PMMA) composite prosthesis: histomorphometric incorporation model and characterization by SEM. Acta Orthop 79: 555-564, 2008.

HEINO TJ, HENTUNEN TA: Differentiation of osteoblasts and osteocytes from mesenchymal stem cells. Curr Stem Cell Res Ther 3: 131-145, 2008.

HOLLAND TA, MIKOS AG: Biodegradable polymeric scaffolds. Improvements in bone tissue engineering through controlled drug delivery. Adv Biochem Eng Biotechnol 102: 161-185, 2006.

KANG YH, JEON SH, PARK JY, CHUNG JH, CHOUNG YH, CHOUNG HW, KIM ES, CHOUNG PH: Platelet-rich fibrin (PRF) is a bio-scaffold and reservoir of growth factors for tissue regeneration. Tissue Eng Part A 17: 349-359, 2011.

KASTEN P, VOGEL J, BEYEN I, WEISS S, NIEMEYER P, LEO A, LÜGINBUHL R: Effect of platelet-rich plasma on the in vitro proliferation and osteogenic differentiation of human mesenchymal stem cells on distinct calcium phosphate scaffolds: the specific surface area makes a difference. J Biomater Appl 23: 169-188, 2008.

KAUNITZ JD, YAMAGUCHI DT: TNAP, TrAP, ecto-purinergic signaling, and bone remodeling. J Cell Biochem 105: 655-662, 2008.

KRUPA P, KRSEK P, JAVORNÍK M, DOSTÁL O, SRNEC R, USVALD D, PROKS P, KECOVÁ H, AMLER E, JANCÁR J, GÁL P, PLÁNKA L, NECAS A: Use of 3D geometry modeling of osteochondrosis-like iatrogenic lesions as a template for press-and-fit scaffold seeded with mesenchymal stem cells. Physiol Res 56: S107S114, 2007.

LEE KB, HUI JH, SONG IC, ARDANY L, LEE EH: Injectable mesenchymal stem cell therapy for large cartilage defects--a porcine model. Stem Cells 25: 2964-2971, 2007.

LIU G, HU YY, ZHAO JN, WU SJ, XIONG Z, LU R: Effect of type I collagen on the adhesion, proliferation, and osteoblastic gene expression of bone marrow-derived mesenchymal stem cells. Chin J Traumatol 7: 358-362, 2004.

LONG MW: Osteogenesis and bone-marrow-derived cells. Blood Cells Mol Dis 27: 677-690, 2001.

MOTLÍK J, KLÍMA J, DVORÁNKOVÁ B, SMETANA K Jr: Porcine epidermal stem cells as a biomedical model for wound healing and normal/malignant epithelial cell propagation. Theriogenology 67: 105-111, 2007.

NAKAMURA M, IWANAGA S, HENMI C, ARAI K, NISHIYAMA Y: Biomatrices and biomaterials for future developments of bioprinting and biofabrication. Biofabrication 2: 014110, 2010.

PLANKA L, GAL P, KECOVA H, KLIMA J, HLUCILOVA J, FILOVA E, AMLER E, KRUPA P, KREN L, SRNEC R, URBANOVA L, LORENZOVA J, NECAS A: Allogeneic and autogenous transplantations of MSCs in treatment of the physeal bone bridge in rabbits. BMC Biotechnol 8: 70, 2008.

PLÁNKA L, STARÝ D, HLUČILOVÁ J, KLÍMA J, JANČÁŘ J, KŘEN L, LORENZOVÁ J, URBANOVÁ L, CRHA M, SRNEC R, DVOŘÁK M, GÁL P, NEČAS A: Comparison of preventive and therapeutic transplantations of allogeneic mesenchymal stem cells in healing of the distal femoral growth plate cartilage defects in miniature pigs. Acta Vet Brno 78: 293-302, 2009.

POTIER E, FERREIRA E, ANDRIAMANALIJAONA R, PUJOL JP, OUDINA K, LOGEART-AVRAMOGLOU D, PETITE H: Hypoxia affects mesenchymal stromal cell osteogenic differentiation and angiogenic factor expression. Bone 40: 1078-1087, 2007.

QU CQ, ZHANG GH, ZHANG LJ, YANG GS: Osteogenic and adipogenic potential of porcine adipose mesenchymal stem cells. In Vitro Cell Dev Biol Anim 43: 95-100, 2007.

RINGE J, KAPS C, SCHMITT B, BÜSCHER K, BARTEL J, SMOLIAN H, SCHULTZ O, BURMESTER GR, HÄUPL T, SITTINGER M: Porcine mesenchymal stem cells. Induction of distinct mesenchymal cell lineages. Cell Tissue Res 307: 321-327, 2002.

ROMERO-PRADO M, BLÁZQUEZ C, RODRÍGUEZ-NAVAS C, MUÑOZ J, GUERRERO I, DELGADO BAEZA E, GARCÍA-RUIZ JP: Functional characterization of human mesenchymal stem cells that maintain osteochondral fates. J Cell Biochem 98: 1457-1470, 2006. 
SALASZNYK RM, WILLIAMS WA, BOSKEY A, BATORSKY A, PLOPPER GE: Adhesion to vitronectin and collagen I promotes osteogenic differentiation of human mesenchymal stem cells. J Biomed Biotechnol 2004: 24-34, 2004.

SHIH YR, CHEN CN, TSAI SW, WANG YJ, LEE OK: Growth of mesenchymal stem cells on electrospun type I collagen nanofibers. Stem Cells 24: 2391-2397, 2006.

SHIN H, ZYGOURAKIS K, FARACH-CARSON MC, YASZEMSKI MJ, MIKOS AG: Modulation of differentiation and mineralization of marrow stromal cells cultured on biomimetic hydrogels modified with Arg-Gly-Asp containing peptides. J Biomed Mater Res A 69: 535-543, 2004.

SUÁREZ-GONZÁLEZ D, BARNHART K, SAITO E, VANDERBY R Jr, HOLLISTER SJ, MURPHY WL: Controlled nucleation of hydroxyapatite on alginate scaffolds for stem cell-based bone tissue engineering. J Biomed Mater Res A 95: 222-234, 2010.

TEMENOFF JS, PARK H, JABBARI E, SHEFFIELD TL, LEBARON RG, AMBROSE CG, MIKOS AG: In vitro osteogenic differentiation of marrow stromal cells encapsulated in biodegradable hydrogels. $J$ Biomed Mater Res $A$ 70: 235-244, 2004.

TROMBI L, D'ALESSANDRO D, PACINI S, FIORENTINO B, SCARPELLINI M, FAZZI R, GALIMBERTI S, GUAZZINI S, PETRINI M: Good manufacturing practice-grade fibrin gel is useful as a scaffold for human mesenchymal stromal cells and supports in vitro osteogenic differentiation. Transfusion 48: 2246-2251, 2008.

VALENTI MT, DALLE CARBONARE L, DONATELLI L, BERTOLDO F, ZANATTA M, Lo CASCIO V: Gene expression analysis in osteoblastic differentiation from peripheral blood mesenchymal stem cells. Bone 43: 1084-1092, 2008.

VODICKA P, SMETANA K Jr, DVORÁNKOVÁ B, EMERICK T, XU YZ, OUREDNIK J, OUREDNIK V, MOTLÍK J: The miniature pig as an animal model in biomedical research. Ann N Y Acad Sci 1049: 161-171, 2005.

WANG S, LIU Y, FANG D, SHI S: The miniature pig: a useful large animal model for dental and orofacial research. Oral Dis 13: 530-537, 2007.

WANG JJ, YE F, CHENG LJ, SHI YJ, BAO J, SUN HQ, WANG W, ZHANG P, BU H: Osteogenic differentiation of mesenchymal stem cells promoted by overexpression of connective tissue growth factor. J Zhejiang Univ Sci B 10: 355-367, 2009.

XU XL, LOU J, TANG T, NG KW, ZHANG J, YU C, DAI K: Evaluation of different scaffolds for BMP-2 genetic orthopedic tissue engineering. J Biomed Mater Res B Appl Biomater 75: 289-303, 2005.

YILDIRIM ED, BESUNDER R, PAPPAS D, ALLEN F, GÜÇERI S, SUN W: Accelerated differentiation of osteoblast cells on polycaprolactone scaffolds driven by a combined effect of protein coating and plasma modification. Biofabrication 2: 014109, 2010.

ZOU L, ZOU X, CHEN L, LI H, MYGIND T, KASSEM M, BÜNGER C: Multilineage differentiation of porcine bone marrow stromal cells associated with specific gene expression pattern. J Orthop Res 26: 56-64, 2008. 